\title{
Parkinson's Disease: Increased Motor Network Activity in the Absence of Movement
}

\author{
Ji Hyun Ko, Hideo Mure, Chris C. Tang, Yilong Ma, Vijay Dhawan, Phoebe Spetsieris, and David Eidelberg \\ Center for Neurosciences, Feinstein Institute for Medical Research, Manhasset, New York 11030
}

We used a network approach to assess systems-level abnormalities in motor activation in humans with Parkinson's disease (PD). This was done by measuring the expression of the normal movement-related activation pattern (NMRP), a previously validated activation network deployed by healthy subjects during motor performance. In this study, NMRP expression was prospectively quantified in ${ }^{15} 0$-water PET scans from a PD patient cohort comprised of a longitudinal early-stage group $(n=12)$ scanned at baseline and at two or three follow-up visits two years apart, and a moderately advanced group scanned on and off treatment with either subthalamic nucleus deep brain stimulation $(n=14)$ or intravenous levodopa infusion $(n=14)$. For each subject and condition, we measured NMRP expression during both movement and rest. Resting expression of the abnormal PD-related metabolic covariance pattern was likewise determined in the same subjects. NMRP expression was abnormally elevated $(p<0.001)$ in PD patients scanned in the nonmovement rest state. By contrast, network activity measured during movement did not differ from normal $(p=0.34)$. In the longitudinal cohort, abnormal increases in resting NMRP expression were evident at the earliest clinical stages $(p<0.05)$, which progressed significantly over time $(p=0.003)$. Analogous network changes were present at baseline in the treatment cohort $(p=0.001)$. These abnormalities improved with subthalamic nucleus stimulation $(p<0.005)$ but not levodopa $(p=0.25)$. In both cohorts, the changes in NMRP expression that were observed did not correlate with concurrent PD-related metabolic covariance pattern measurements $(p>0.22)$. Thus, the resting state in PD is characterized by changes in the activity of normal as well as pathological brain networks.

\section{Introduction}

Network analysis of functional imaging data acquired in the rest state has provided valuable insights into the network abnormalities underlying Parkinson's disease (PD) and the modulation of these changes by treatment (Eidelberg, 2009). For example, the PD-related spatial covariance pattern (PDRP), an abnormal large-scale metabolic network associated with the akinetic-rigid manifestations of the disorder (Spetsieris and Eidelberg, 2011), has been linked to disease-related changes in basal ganglia output pathways (e.g., Lin et al., 2008; Mure et al., 2011; Niethammer and Eidelberg, 2012).

Although neurodegenerative disorders can be associated with the expression of pathological metabolic patterns in the rest state, the underlying disease process can also influence the activity of

\footnotetext{
Received 0ct. 26, 2012; revised Dec. 20, 2012; accepted Jan. 16, 2013.

Author contributions: J.H.K. and D.E. designed research; J.H.K., H.M., and V.D. performed research; J.H.K., C.C.T., Y.M., V.D., P.S., and D.E. analyzed data; J.H.K. and D.E. wrote the paper.

This work was supported by the National Institutes of Health Grant R01 NS 35069 to D.E. and in part by the National Institute of Neurological Disorders and Stroke Grant P50 NS 071675 (Morris K. Udall Center of Excellence for Parkinson's Disease Research at the Feinstein Institute for Medical Research) to D.E. The content is solely the responsibility of the authors and does not necessarily represent the official views of the National Institute of Neurological Disorders and Stroke or the National Institutes of Health. The sponsor did not play a role in study design, collection, analysis and interpretation of data, writing of the report or in the decision to submit the paper for publication. We thank Dr. Thomas Chaly and Claude Margouleff for technical support and Yoon Young Choi and Toni Fitzpatrick for valuable assistance with manuscript preparation/editing.

The authors declare no competing financial interests.

Correspondence should be addressed to Dr. David Eidelberg, Center for Neurosciences, Feinstein Institute for Medical Research, 350 Community Drive, Manhasset, NY 11030. E-mail: david1@nshs.edu.

DOI:10.1523/JNEUROSCI.5024-12.2013

Copyright $\odot 2013$ the authors $\quad 0270-6474 / 13 / 334540-10 \$ 15.00 / 0$
}

normal brain networks (i.e., those routinely deployed by healthy individuals during task performance) (e.g., Nakamura et al., 2001; Mentis et al., 2003b; compare Pievani et al., 2011). In the case of $\mathrm{PD}$, the status of networks normally activated during the execution of simple movements becomes relevant. The akineticrigid manifestations of PD have been linked to failed suppression of cortical movement-related neural activity in the resting condition (Ridding et al., 1995; Berardelli et al., 1996; Van Der Werf and Paus, 2006; Van Der Werf et al., 2006). By the same token, treatment with either dopaminergic agents or with deep brain stimulation (DBS) can restore cortical inhibition to varying degrees (Chen et al., 2001; Pierantozzi et al., 2002; Lefaucheur, 2005; Fraix et al., 2008). It is not known, however, whether analogous network-level changes can be discerned in the PD rest state.

To address this issue, we measured the expression of a specific movement-related activation network that we have previously reported in healthy subjects (Carbon et al., 2010; Mure et al., 2012). Using a supervised multivariate approach (Habeck et al., $2005)$ to analyze ${ }^{15} \mathrm{O}$-water $\left(\mathrm{H}_{2}{ }^{15} \mathrm{O}\right)$ PET scans from normal volunteers acquired during movement and rest, we identified a highly replicable activation network, which was termed the normal movement-related activation pattern (NMRP). Apart from delineating the spatial topography of this covariance pattern, the algorithm was used to quantify pattern expression on a prospective scan basis, yielding separate network activity measurements for the movement and rest states. In this context, failure to inhibit motor network activity in the absence of movement would be manifest by resting elevations in NMRP expression. To test this hypothesis, we measured network activity in PD patients scanned 
Table 1. Demographic and clinical features ${ }^{a}$

\begin{tabular}{|c|c|c|c|c|c|c|}
\hline & \multicolumn{3}{|c|}{ Early PD (Group 1) } & \multicolumn{2}{|l|}{ Moderate PD (Group 2) } & \multirow[b]{2}{*}{ Normal (Group 3) } \\
\hline & TP1 & TP2 & TP3 & STN DBS & Levodopa & \\
\hline Age (years) & $60.2 \pm 2.0$ & $62.5 \pm 2.0$ & $64.3 \pm 3.1$ & $58.6 \pm 2.8$ & $57.1 \pm 2.0$ & $53.8 \pm 4.7$ \\
\hline Hoehn and Yahr & $1.17 \pm 0.07$ & $2.13 \pm 0.09$ & $2.17 \pm 0.17$ & $2.57 \pm 0.15$ & $2.29 \pm 0.19$ & - \\
\hline UPDRS-III & OFF & OFF & OFF & OFF/ON & OFF/ON & - \\
\hline Total motor & $9.00 \pm 1.40$ & $14.4 \pm 1.45$ & $18.4 \pm 2.91$ & $25.5 \pm 2.22 / 18.0 \pm 1.66$ & $25.4 \pm 2.01 / 16.5 \pm 1.42$ & - \\
\hline Tremor & $1.73 \pm 0.58$ & $2.43 \pm 0.87$ & $1.75 \pm 0.63$ & $3.96 \pm 0.83 / 1.00 \pm 0.28$ & $2.41 \pm 0.73 / 0.81 \pm 0.34$ & - \\
\hline
\end{tabular}

${ }^{a}$ Values are mean $\pm S E$.

-, Not applicable.

at rest and during movement. In addition to comparing these measures to corresponding healthy control values, we evaluated the network changes that occurred with advancing disease and in response to treatment. Last, we correlated the observed NMRP changes with concurrent PDRP measurements from the same subjects and assessed the relationship of the two networks to clinical outcome.

\section{Materials and Methods}

\section{Subjects}

We studied three groups of PD patients with akinetic-rigid predominant symptoms. A diagnosis of PD was made clinically according to United Kingdom Parkinson's Disease Society Brain Bank criteria (Hughes et al., 1992). Patients with tremor-dominant clinical manifestations (composite Unified Parkinson's Disease Rating Scale [UPDRS] limb tremor ratings $\geq 4$ with at least one limb $\geq 2$ ) (Isaias et al., 2010; Mure et al., 2011) were excluded as were subjects with Mini-Mental State Examination scores $<27$. Further exclusion criteria included severe hypertension, cardiovascular disease, diabetes mellitus, and past or current psychiatric history. Review of routine anatomical magnetic resonance imaging from the subjects revealed no evidence of atrophy or incidental structural brain abnormalities. Ethical permission for all studies was obtained from the Institutional Review Board of North Shore University Hospital. Written consent was obtained from each subject after detailed explanation of the procedures.

Group 1: longitudinal cohort. The clinical features of the longitudinal cohort are presented in Table 1 . This cohort consisted of 12 right-handed early-stage PD patients (age 60.2 \pm 2.0 years, mean $\pm \mathrm{SD}$; off-state UPDRS motor ratings $9.0 \pm 1.4$ ) with predominantly akinetic-rigid clinical manifestations. These subjects underwent $\mathrm{H}_{2}{ }^{15} \mathrm{O}$ PET at baseline (TP1) and again at a second time point (TP2) $2.4 \pm 0.3$ years later. Six of these subjects were rescanned at a third time point (TP3) $4.4 \pm 0.3$ years after baseline. All subjects in this group had unilateral motor signs ("hemiparkinsonism") at baseline. At TP1, seven of the subjects exhibited clinical manifestations on the right side; the remainder had signs on the left side. At TP2, motor ratings increased to $14.4 \pm 1.5$ and to $18.4 \pm$ 2.9 for those scanned at TP3. At baseline, five subjects were drug-naive, six were on levodopa/carbidopa, dopamine agonists, or both; the remaining subject was on deprenyl. By TP2, all subjects but one were on chronic oral dopaminergic treatment. In the treated patients, antiparkinsonian medications were discontinued $12 \mathrm{~h}$ before PET imaging. At each longitudinal time point, the subjects additionally underwent metabolic brain imaging with $\left[{ }^{18} \mathrm{~F}\right]$-fluorodeoxyglucose (FDG) PET for the measurement of PDRP expression in the rest state. Limited imaging data from these subjects have been reported previously (Carbon et al., 2007; Huang et al., 2007; Tang et al., 2010).

Group 2: treatment cohort. The clinical features of this cohort are presented in Table 1. The first treatment subgroup (Group 2A) consisted of 14 right-handed moderately advanced PD patients (age 58.6 \pm 2.8 years; off-state motor UPDRS $25.5 \pm 2.2$ ). These patients were on chronic bilateral subthalamic nucleus (STN) stimulation for predominant akinesia-rigidity; they underwent $\mathrm{H}_{2}{ }^{15} \mathrm{O}$ PET at baseline and again during stimulation. The baseline (OFF) condition was defined as $12 \mathrm{~h}$ after the cessation of medication and at least $1 \mathrm{~h}$ after stimulators were turned off.
The treatment (DBS) condition was defined by adjusting the stimulation parameters on both sides to achieve an improvement in motor UPDRS ratings of at least 5 points and/or a reduction of $20 \%$ relative to the baseline condition. In this subgroup, treatment was associated with a change in motor UPDRS ratings of $-7.4 \pm 1.3$ points $(-20.2 \%, p<$ 0.001 ; paired Student's $t$ test). Of these subjects, 10 additionally underwent FDG PET imaging to measure resting PDRP expression in the two treatment conditions. Limited imaging data from these subjects have been reported previously (Asanuma et al., 2006; Hirano et al., 2008; Mure et al., 2012).

The second treatment subgroup (Group 2B) consisted of 14 righthanded moderately advanced PD patients (age $57.1 \pm 2.0$ years; off-state motor UPDRS $25.4 \pm 2.0$ ) who were scanned in a baseline condition (OFF) after a $12 \mathrm{~h}$ medication washout and during an intravenous levodopa infusion (LD) that was titrated to achieve a stable treatment response with minimal or no dyskinesia. The details of the levodopa infusion protocol have been provided previously (Hirano et al., 2008; Mure et al., 2012). In this subgroup, treatment was associated with a change in motor UPDRS ratings of $-8.9 \pm 1.3$ points $(-35.1 \%, p<$ 0.001; paired Student's $t$ test). Of these subjects, six also underwent FDG PET at baseline and during levodopa infusion. Limited imaging data from these subjects have been reported previously (Argyelan et al., 2008; Hirano et al., 2008; Mure et al., 2012).

Group 3: healthy control subjects. This group consisted of eight righthanded normal volunteers (age $53.8 \pm 4.7$ years) who were scanned with $\mathrm{H}_{2}{ }^{15} \mathrm{O}$ PET at a single time point. These individuals were not among the 18 healthy subjects whose scans were used originally for NMRP derivation (Carbon et al., 2010). Rather, $\mathrm{H}_{2}{ }^{15} \mathrm{O}$ PET scans from the current normal control group were used to measure network activity prospectively on a subject-by-subject basis (see below). The resulting NMRP expression values were compared with the corresponding measures from the PD patients computed in the different experimental conditions.

\section{Imaging procedures}

PET imaging was performed in 3D mode using a GE Advance tomograph (General Electric). The 18-ring bismuth germanate scanner provided 35 image planes with an axial field of view of $14.5 \mathrm{~cm}$ and an intrinsic resolution of $4.2 \mathrm{~mm}$ (FWHM) in all directions. PET scans were conducted in a dimly lit room with minimal auditory stimulation with eyes open. Patients were positioned in the scanner using a stereoadapter with $3 \mathrm{D}$ laser alignment with reference to the orbitomeatal line; identical stereoadapter and laser settings were used in each imaging session.

Subjects were scanned with $\mathrm{H}_{2}{ }^{15} \mathrm{O}$ PET in each experimental condition (time point for Group 1; treatment condition for Group 2; baseline session for Group 3) while performing a kinematically controlled motor execution task (MOVE) in which reaching movements were made toward a circular array of targets (Ghilardi et al., 2000). In MOVE, the subjects moved a cursor on a digitizing tablet with the dominant right hand. Movements were out and back from a central starting position to one of eight radial targets displayed on the screen. The eight targets appeared in a predictable counter-clockwise order. To reach the target in synchrony with the tone, subjects had to initiate movement before it appeared. For each subject, the extent and rate of the movements were adjusted to be kinematically equivalent across trials and conditions (e.g., Argyelan et al., 2008; Mure et al., 2012). The subjects were also scanned 


\section{A NMRP}

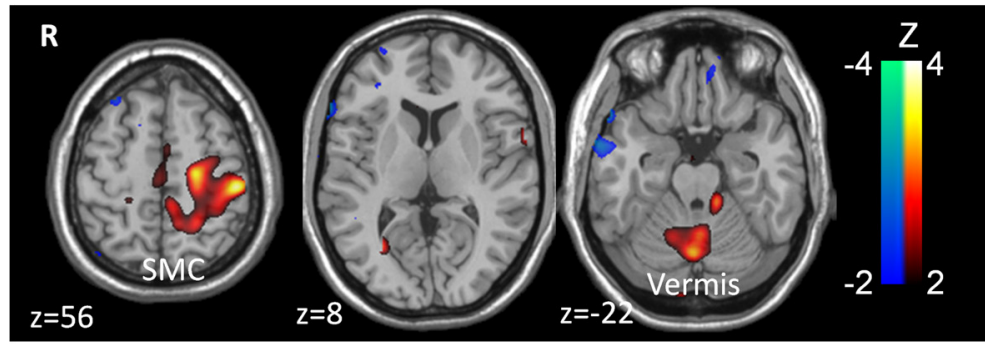

\section{B PDRP}

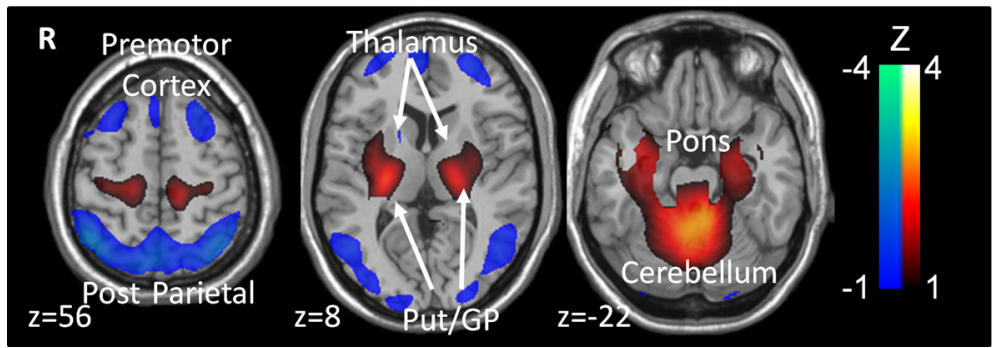

\section{Voxel-wise Correlation of the Two Pattern Topographies}

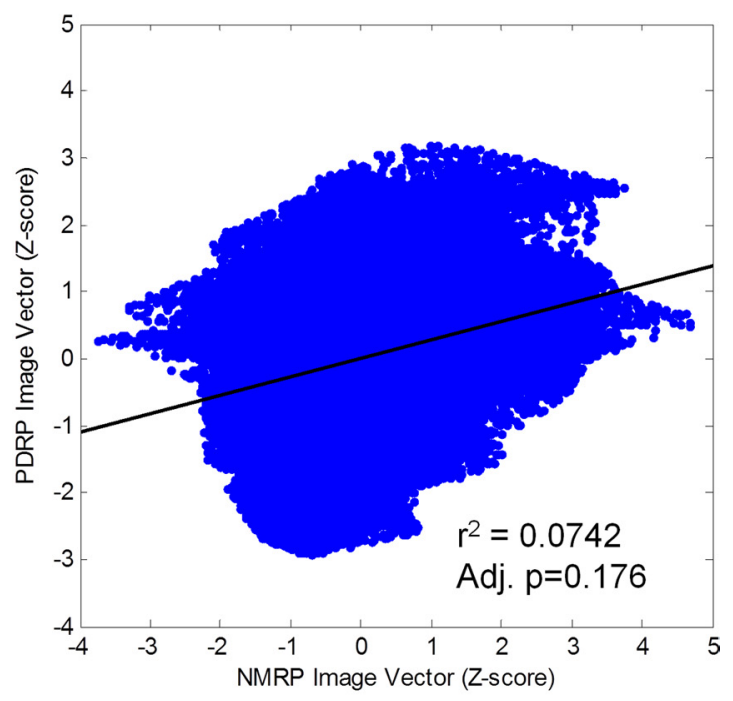

Figure 1. Spatial covariance patterns: the NMRP and PDRP topographies. $A$, NMRP identified by network analysis of 39 MOVE and NO MOVE $\mathrm{H}_{2}{ }^{15} 0$ PET scan pairs from 18 healthy volunteer subjects (Carbon et al., 2010; Mure et al., 2012). This spatial covariance pattern was characterized by activation of the left sensorimotor cortex (SMC), premotor cortex, and inferior parietal cortex. Additional contributions to this activation topography were found bilaterally in the cerebellar vermis and paramedian zone. The displayed voxel loadings on the pattern were shown to be reliable $(p<0.001$ ) using bootstrap estimation procedures. B, PDRP identified by spatial covariance analysis of FDG PET metabolic images from a combined group of 33 PD patients and 33 controls (Ma et al., 2007; Eidelberg, 2009). This pattern was characterized by increased (red) pallidal, thalamic, and motor cortical metabolic activities associated with reduced (blue) lateral premotor and parieto-occipital cortical activities. The displayed voxel loadings on the pattern were shown to be reliable ( $p<0.001$ ) by bootstrap estimation. $C$, Voxelwise correlation of standardized regional loadings on the two spatial covariance patterns (Mure et al., 2011). The NMRP and PDRP exhibited minimal spatial correspondence, with $<7.5 \%$ of the total variation in voxel weights shared by the two topographies. This correlation did not differ from chance ( $p=0.176)$.

during NO MOVE, a nonmovement reference condition in which they passively observed randomly appearing targets. All longitudinal (Group 1) and levodopa infusion (Group 2B) subjects were scanned during both MOVE and NO MOVE. All 14 members of the STN stimulation cohort (Group 2A) were scanned without movement in the OFF and DBS conditions; eight were scanned in the two treatment conditions during both movement and rest.

\section{Network analysis}

NMRP. We used Ordinal Trends Canonical Variates Analysis (OrT/ CVA), a within-group network modeling approach (Habeck et al., 2005; Moeller and Habeck, 2006) (software available at http://groups.google. com/group/gCVA), to identify and validate the spatial covariance topography associated with motor activation in healthy subjects. OrT/CVA is a specialized form of supervised principal component analysis that searches for the presence of specific patterns of functional connectivity (i.e., large-scale brain networks) in serial imaging data acquired over multiple ordered experimental conditions. The analysis searches for spatial covariance patterns (i.e., the principal components) for which the associated subject scores (i.e., the principal component scalars) exhibit monotonically increasing expression across conditions, even as the functional relationship between the brain regions comprising the network remains constant (i.e., is group invariate). This approach is fundamentally different from routine mass-univariate analysis in which task-related changes in individual regions (clusters) are evaluated independently at the group mean level (Moeller and Habeck, 2006). OrT/CVA identifies brain networks that, if present in the data, exhibit consistent increases in subject expression across tasks or experimental conditions in all or most cases. This property is known as an ordinal trend. The presence of a significant ordinal trend in a given dataset is determined nonparametrically by permutation testing of the relevant subject scores to reject the possibility that the observed changes in pattern expression across conditions had occurred by chance. Likewise, the reliability of the regional contributions to the network topography (i.e., the voxel loadings on the pattern) is assessed by bootstrap estimation (Ha- beck and Stern, 2010). Importantly, the test-retest reliability of pattern expression within individual subjects is evaluated across repeat runs obtained in each condition.

In addition to quantifying the expression of the resulting pattern(s) in each subject and condition in the derivation cohort, OrT/CVA can also be used prospectively to measure network activity in new subjects/conditions on an individual scan basis. In the current study, we used the previously validated NMRP topography (Fig. $1 A$ ) identified by OrT/CVA of $\mathrm{H}_{2}{ }^{15} \mathrm{O}$ PET data from 18 healthy subjects scanned during both MOVE and NO MOVE (Carbon et al., 2010; Mure et al., 2012). This pattern exhibited only minimal correspondence with the PDRP topography (Fig. $1 B$ ), sharing only $7.4 \%$ of the variance in their respective voxel weights ( $p=0.176$, adjusted; see below). Here, we quantified NMRP activity in the MOVE and NO MOVE scans (referred to as NMRP [MOVE] and NMRP [NO MOVE] values, respectively) from all groups, subjects, and experimental conditions. For the early-stage longitudinal cohort (Group 1), network values were computed in MOVE and NO MOVE scans at each time point. For the treatment cohort (Group 2), NMRP [MOVE] and NMRP [NO MOVE] values were computed in scans acquired at baseline and during treatment with either STN stimulation (Group 2A) or levodopa infusion (Group 2B). We also computed NMRP [MOVE] and NMRP [NO MOVE] values in the scans acquired in the new healthy volunteer cohort (Group 3). To standardize measurements of network activity across subjects, tasks, and experimental conditions, computed values were $z$-scored with respect to NMRP expression in the NO MOVE scans $(n=39)$ of the original derivation cohort such that the mean for this sample was 0 and the SD was 1 .

For validation, we demonstrated the presence of a significant ordinal trend (NMRP [MOVE] > NMRP [NO MOVE]) in the current dataset. This was done separately for each group and experimental condition by evaluating each MOVE and NO MOVE scan pair individually and counting the number of exceptions (violations) to the ordinal trend (i.e., scan pairs for which NMRP [MOVE] $\leq$ NMRP [NO MOVE] ) in relation to the total number of trials. In each sample, the null hypothesis that the 
Table 2. Atremulous and tremulous patients ${ }^{a}$

\begin{tabular}{lllr}
\hline & Atremulous & Tremulous & $p^{b}$ \\
\hline Age (years) & $58.8 \pm 2.9$ & $59.6 \pm 1.9$ & 0.829 \\
Male:female & $7: 3$ & $7: 3$ & \\
Hoehn and Yahr & $1.99 \pm 0.17$ & $1.74 \pm 0.18$ & 0.326 \\
UPDRS-III & $15.24 \pm 2.86$ & $17.02 \pm 1.34$ & 0.581 \\
Rest tremor & $0.00 \pm 0.00$ & $1.84 \pm 0.24$ & $<0.001$ \\
Akinesia-rigidity & $11.00 \pm 2.68$ & $10.61 \pm 1.24$ & 0.901 \\
\hline
\end{tabular}

${ }^{a}$ Values are mean $\pm \mathrm{SE}$.

${ }^{b}$ Atremulous versus tremulous groups (Student's t test).

observed distribution of NMRP [MOVE] - NMRP [NO MOVE] differences was explainable by chance was examined using binomial tests, which were considered significant for $p<0.01$ (Mure et al., 2012). To evaluate the stability of the NMRP measurements, we performed a testretest analysis of the values obtained in repeat trials from the same subject. The test-retest reproducibility of NMRP [MOVE] and NMRP [NO MOVE] values were separately evaluated by computing intraclass correlations (ICC) for each measurement. Values were considered reliable for $p<0.05$.

Last, to determine whether intercurrent tremor influences network expression, we separately compared NMRP [NO MOVE] and NMRP [MOVE] values measured in the atremulous PD subjects $(n=10)$, defined as those with tremor subscale ratings (UPDRS III item 20 and 21) of 0 , with corresponding measurements from a subgroup of PD subjects $(n=10)$ with observable tremor who were matched for both age and composite UPDRS motor ratings (Table 2). Differences in NMRP expression measured in $\mathrm{PD}$ subjects with and without tremor, and in healthy control subjects $(n=8)$, were evaluated using one-way ANOVA and post hoc Bonferroni tests. Differences between groups were considered significant for $p<0.05$.

PDRP expression. In addition to quantifying NMRP activity in MOVE and NO MOVE scans, we also measured resting PDRP expression in FDG PET scans from these subjects. For consistency with previously published measures of PDRP expression, the resulting values were $z$-scored with respect to the values computed in the FDG PET scans of the normal subjects $(n=33)$ used in the original pattern derivation (Ma et al., 2007; Spetsieris and Eidelberg, 2011). All single-case computations were performed using a fully automated voxel-based algorithm (software available at http://www.fil.ion.ucl.ac.uk/spm/ext/\#SSM), blind to group and experimental condition.

\section{Data analysis}

Comparison of the NMRP and PDRP topographies. To evaluate spatial similarities and differences between the NMRP and PDRP topographies, we compared the regional weights on the two spatial covariance patterns using a voxelwise correlational approach (Mure et al., 2011). Spatial autocorrelation can produce chance correlations within the network volumes (Liebhold and Sharov, 1998). To address this concern, we conducted a set of simulations to determine the number of times a correlation of the observed magnitude (i.e., $r^{2}$ for the correlation of the NMRP and PDRP voxel weights) occurred by chance. To do this, we constructed 1000 pseudo-random volume pairs; each volume was comprised of 116 regions defined by the automated anatomical labeling algorithm (Tzourio-Mazoyer et al., 2002). Within a given volume, each region was assigned pseudo-random numbers (Gaussian distribution with mean of 0 and SD of 1). Gaussian noise (mean of 0 and SD of 0.05 ) was added to each volume and smoothed with a box filter of increasing kernel size $(5 \times 5 \times 5$ to $45 \times 45 \times 45$ voxels $)$ to produce an autocorrelation of similar degree to that observed empirically for the two patterns. (The spatial autocorrelation of each volume was estimated by the average of local Moran's I calculated within a test space defined by a common mask constructed to include both patterns.) In each iteration, the generated volumes were correlated; this simulation procedure was repeated 1000 times. We then calculated the rank of the $r^{2}$ value that corresponded to the magnitude of the correlation $\left(r^{2}\right)$ that was directly observed between the two region weight vectors. In the correlation between the NMRP and PDRP voxel weights, 176 volume-pairs exhibited correla- tions of magnitude greater than the observed $r^{2}$ value of 0.074 , which corresponded to $p=0.176$. Thus, the correlation of two network topographies was therefore not statistically significant.

Changes across groups and experimental conditions. NMRP expression values were computed separately in the MOVE and NO MOVE scans obtained for each subject and experimental condition. Additionally, these values were used to compute $\triangle$ NMRP, the MOVE - NO MOVE difference in NMRP expression, corresponding to the network-level motor activation response for each subject and condition. Group differences in NMRP [MOVE], NMRP [NO MOVE], and $\triangle$ NMRP [MOVE - NO MOVE] were assessed separately by comparing the respective network values for the early-stage (Group 1 scans averaged across the three longitudinal time points) and the more advanced (Group 2 scans acquired in the baseline untreated condition) PD cohorts, and in the healthy control group (Group 3) using one-way ANOVA with post hoc Bonferroni tests. This analysis is repeated using subject age as a covariate. We additionally compared the group differences in NMRP [MOVE] expression with those for NMRP [NO MOVE] to determine whether a significant group $\times$ task interaction effect was present in the data. This was accomplished using $2 \times 3$ repeated-measures ANOVA.

Within-group analyses were performed to assess the changes in network expression that occurred over time (Group 1) and during treatment (Group 2). For Group 1 patients, longitudinal changes in pattern expression were evaluated for NMRP [MOVE], NMRP [NO MOVE], and $\triangle$ NMRP [MOVE - NO MOVE]. The time course of each network measure was evaluated using the general linear model (GLM) (McClullagh and Nelder, 1989). The trajectories of the values over time were compared for each pair of network activity measures by computing Bland-Altman within-subject correlation coefficients (Bland and Altman, 1995). Additionally, cross-sectional relationships between NMRP and PDRP expression values were separately examined for each longitudinal time point by computing Pearson productmoment correlation coefficients.

Treatment effects. A similar approach was used to evaluate changes in NMRP expression during treatment. For each subgroup (Group 2A: STN stimulation; Group 2B: levodopa infusion), NMRP [MOVE], NMRP [NO MOVE], and $\triangle \mathrm{NMRP}$ [MOVE - NO MOVE] values were computed in the baseline (OFF) and treatment (DBS or LD) conditions, and compared with corresponding healthy control values using Student's $t$ tests. Treatment-mediated changes in each network measure were evaluated using paired Student's $t$ tests. Correlations between NMRP and PDRP expression were assessed in the subjects who underwent imaging with both $\mathrm{H}_{2}{ }^{15} \mathrm{O}$ and FDG PET; separate Pearson product-moment correlation coefficients were computed for scans acquired in the baseline off-state and during treatment. The relationship between treatmentmediated changes in the expression of the two networks was evaluated using correlation analysis. This analysis was limited to the subset of Group 2 subjects (10 STN DBS; 6 levodopa) who underwent imaging with both FDG and $\mathrm{H}_{2}{ }^{15} \mathrm{O}$ PET in the baseline and treatment conditions.

Clinical correlates. We used the GLM to determine whether the changes in UPDRS motor ratings over time (Group 1) or with treatment (Groups 2) correlated with concurrent measurements of NMRP [NO MOVE] and/or PDRP network activity. The following linear models were evaluated for the two groups separately: (1) UPDRS = $\mathrm{B}^{\star}$ subjects $[2 \ldots n]+\mathrm{c} ;(2)$ UPDRS $=\mathrm{B}^{\star}$ subjects $[2 \ldots n]+\mathrm{b} 1^{\star} \mathrm{PDRP}+\mathrm{c}$; (3) UPDRS $=\mathrm{B}^{\star}$ subjects $[2 \ldots n]+\mathrm{b} 1^{\star} \mathrm{NMRP}+\mathrm{c}$; and (4) UPDRS $=$ $\mathrm{B}^{\star}$ subjects $[2 \ldots n]+\mathrm{b} 1^{\star} \mathrm{PDRP}+\mathrm{b} 2^{\star} \mathrm{NMRP}+\mathrm{c}$.

The models were tested hierarchically to determine whether clinical outcome was more accurately predicted using the two networks together as opposed to each separately. This approach provided quantitative information concerning the relative contributions of each network predictor to clinical severity as well as potential overlap between these variables. The Matlab 7.7.0 statistical toolbox was used for the GLM analyses. SPSS 13.0 for Windows was used for the remaining statistical analyses. Results were considered significant for $p<0.05$. 


\section{A Healthy Subjects}

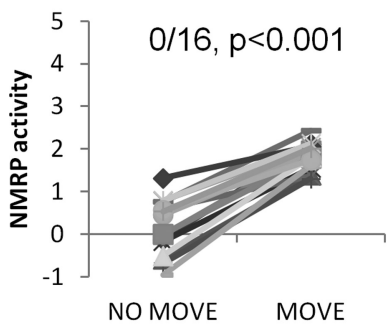

C STN Stimulation
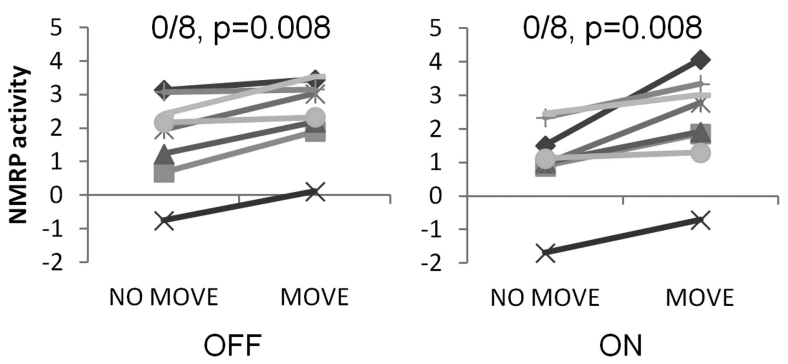

\section{B Disease Progression}

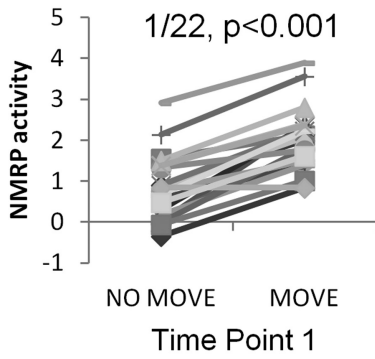

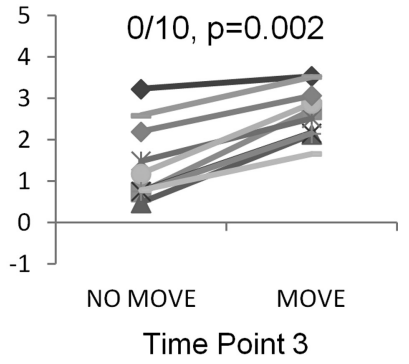

D Levodopa Infusion

Figure 2. Prospective computations of NMRP expression: confirmation of ordinal trend. Prospectively computed measures of NMRP expression in MOVE and NO MOVE scans from the following: $(\boldsymbol{A})$ healthy volunteer subjects, $(\boldsymbol{B})$ early-stage PD patients scanned at each time point, $(\boldsymbol{C})$ moderate-stage PD patients scanned on and off STN stimulation, and ( $\boldsymbol{D})$ moderate-stage PD patients scanned on and off levodopa infusion. The prospective healthy control group exhibited an increase in NMRP expression in all MOVE/NO MOVE trials. In the PD group, the MOVE $>$ NO MOVE ordinal trend was confirmed in each of the groups and experimental conditions ( $p<0.01$; binomial tests), with three violations of a total of 105 trials (see Results).

\section{Results}

Quantification of NMRP expression in individual subjects: validation

We first verified that the NMRP was consistently activated by movement in each of the groups and experimental conditions analyzed in this study. To confirm the presence of an ordinal trend in NMRP expression across tasks, we quantified network activity in each MOVE/NO MOVE scan pair and determined the number of violations (i.e., trials in which NMRP [MOVE] $\leq$ NMRP [NO MOVE]) that were present in each of the samples (see Materials and Methods). Indeed, NMRP expression in MOVE exceeded NO MOVE in each group/condition (Fig. 2) with few, if any, violations (Group 1: TP1, 1 violation in 22 [ 1 of 22 ] trials, $p<0.001$; TP2, 0 of 17, $p<0.001$; TP3, 0 of 10, $p=0.002$; Group 2A: OFF, 0 of 8 ; DBS, 0 of 8, $p=0.008$; Group 2B: OFF, 0 of 20 ; LD, 2 of 20 , $p<0.001$; Group 3: 0 of 16, $p<0.001$; binomial tests). We next assessed the within-subject stability of prospectively computed NMRP expression values. These measures exhibited excellent test-retest reliability in repeat trials conducted during MOVE (ICC $=0.89, p<0.001 ; 55$ test-retest scan pairs) and NO MOVE (ICC $=0.91, p<0.001 ; 51$ test-retest scan pairs). Because of the close correlation that was found in repeat scans obtained in a given subject and condition, the corresponding network values were averaged for further analysis.

Last, because different normative samples were used to standardize measurements of NMRP and PDRP expression, we considered the possibility of bias in the comparisons of the (post hoc Bonferroni test).
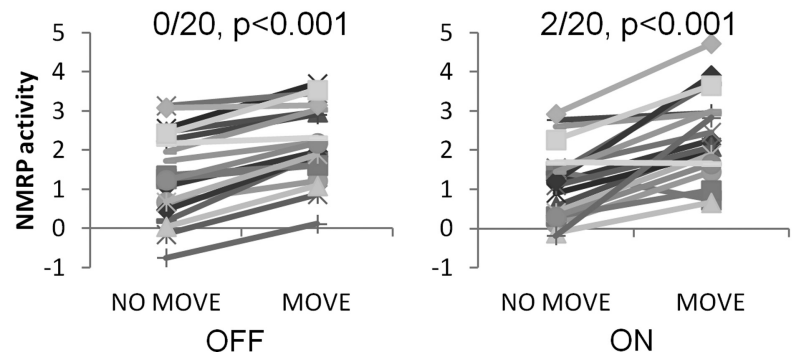

Figure 3. Abnormal NMRP expression in PD. $A$, NMRP expression measured in the NO MOVE condition was increased in early (EARLY) and in moderately advanced (MOD) PD $\left(F_{(2,37)}=7.881, p=0.001\right.$; one-way ANOVA), with significant between the two PD groups ( $p=0.821)$. $\boldsymbol{B}$, Group differences in NMRP expression measured during motor execution (MOVE) were not significant $\left(F_{(2,33)}=1.116, p=0.340\right)$. C, A significant difference across groups was noted for $\triangle$ NMRP, each subject $\left(F_{(2,33)}=8.699, p=0.001\right)$. $\Delta$ NMRP was reduced relative to control values for both PD groups (EARLY: $p=$ 0.033 , MOD: $p=0.001$; post hoc Bonferroni test). NMRP expression values was $z$-scored with respect to the NO MOVE scans $(n=39)$ of the original derivation cohort (see Materials and Methods). ${ }^{*} p<0.05$ (post hoc Bonferroni test). ${ }^{* *} p<0.01$

corresponding subject scores. We therefore compared $z$-scored NMRP [NO MOVE] and resting PDRP expression values measured in the six Group 3 normatives who were scanned with both $\mathrm{H}_{2}{ }^{15} \mathrm{O}$ and FDG PET. The resulting network values disclosed no evidence of bias (NMRP [NO MOVE]: $0.24 \pm 0.26$; PDRP: $0.22 \pm 0.25, p=0.93$ ) from the different control samples used to standardize the two variables. These values were therefore directly compared without recalibration.

\section{Differences in NMRP expression across groups}

NMRP expression measured in the NO MOVE scans of earlystage and moderately advanced PD patients (Fig. 3A) differed from corresponding healthy control values $\left(F_{(2,37)}=7.881, p=\right.$ 0.001 ; one-way ANOVA), with abnormal elevations in both patient groups relative to healthy control values (early PD: $p=$ 

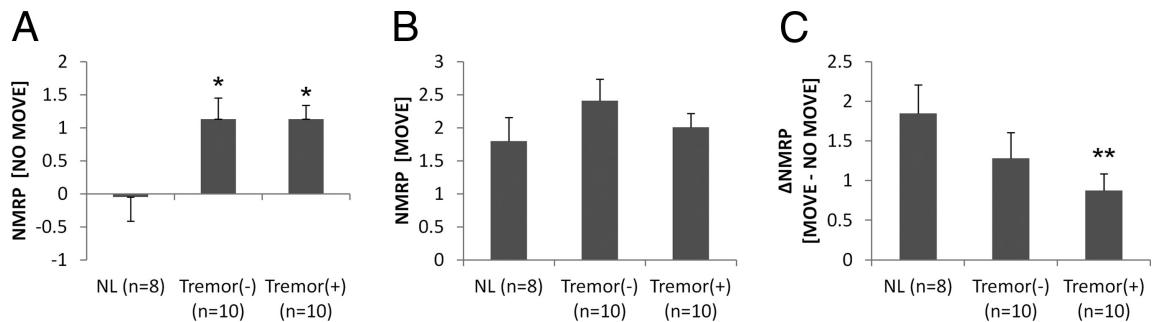

Figure 4. NMRP expression PD: absence of tremor effect. NMRP expression values computed in atremulous (Tremor( -$)$ ) PD patients were compared with corresponding values from their age- and severity-matched counterparts with observable tremor $(\operatorname{Tremor}(+))$ as well as measurements in normal $(\mathrm{NL})$ control subjects. $\boldsymbol{A}$, Pattern expression in the nonmovement condition (NMRP [NO MOVE]) was increased to similar levels in tremulous and atremulous patients, with significant elevations in both PD subgroups relative to healthy control values $(p<0.04)$. $B$, Group differences in NMRP expression measured during motor execution (MOVE) were not significant $\left(F_{(2,25)}=1.421, p=0.260\right)$. C, A significant difference across groups was noted for $\Delta$ NMRP [MOVE - NO MOVE], the network-level motor activation response $\left(F_{(2,25)}=7.533, p=0.003\right) . \Delta$ NMRP was abnormally reduced in the tremulous PD subgroup ( $p=0.002$; post hoc Bonferroni test). A trend-level reduction $(p=0.1)$ in $\Delta N M R P$ was evident in the atremulous PD subgroup relative to healthy control subjects. The two PD subgroups, however, did not differ with respect to this measure $(p=0.293) .{ }^{*} p<0.05$ (post hoc Bonferroni test). ${ }^{* *} p<0.01$ (post hoc Bonferroni test).
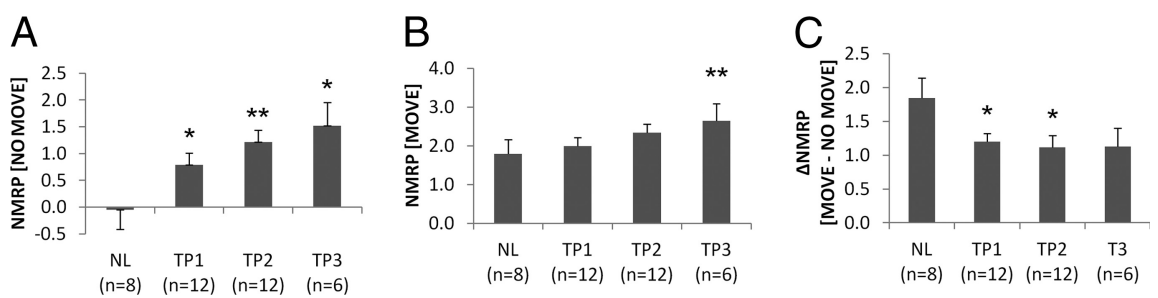

Figure 5. Longitudinal changes in NMRP expression. $\boldsymbol{A}$, NMRP expression measured in nonmovement (NO MOVE) scans was elevated relative to healthy control (NL) values at each of the longitudinal time points (TP1: $t_{(18)}=2.108, p=0.049 ; \mathrm{TP}_{2: t_{(18)}}=$ $3.180, p=0.005$; TP3: $\left.t_{(12)}=2.786, p=0.016\right)$. Within subjects, these values significantly increased with disease progression $\left(t_{(17)}=3.487, p=0.0028\right.$; general linear model). $\boldsymbol{B}$, In the MOVE scans, by contrast, the NMRP elevations reached significance with respect to control values only at the final time point $\left(\mathrm{TP} 1: t_{(18)}=0.735, p=0.472 ; \mathrm{TP2}: t_{(18)}=1.610, p=0.125 ; \mathrm{TP3}: t_{(12)}=\right.$ 3.676, $p=0.003)$. C, The $\Delta$ NMRP activation responses were significantly reduced at the first two time points (TP1: $t_{(18)}=$ $\left.-2.272, p=0.036 ; \mathrm{TP} 2: t_{(18)}=-2.274, p=0.035 ; \mathrm{TP} 3: t_{(12)}=-1.713, p=0.112\right)$. NMRP expression in MOVE and NO MOVE increased in parallel over time ( $r=0.70, p<0.001$; Bland-Altman correlation). Accordingly, the longitudinal change in $\Delta N M R P$ values was not significant $\left(t_{(17)}=0.002, p=0.998\right) .{ }^{*} p<0.05$, compared with NL (Student's t test). ${ }^{* *} p<0.01$, compared with $\mathrm{NL}$ (Student's $t$ test).

0.028; moderate PD: $p=0.001$; post hoc Bonferroni tests). This group difference remained significant after adjustment for variation in subject age $\left(F_{(2,36)}=7.184, p=0.002\right)$. By contrast, the profile of pattern expression across groups for NMRP [MOVE] (Fig. 3B) differed from NMRP [NO MOVE], with no significant between-group difference in network activity measured during movement $\left(F_{(2,33)}=1.116, p=0.340\right)$. Of note, a significant group difference in $\triangle$ NMRP [MOVE - NO MOVE] values (Fig. $3 C$ ) was noted across the three groups $\left(F_{(2,33)}=8.699, p=0.001\right)$. Network-level activation responses were reduced in both patient groups relative to the healthy control subjects (early PD: $p=0.033$; moderate PD: $p=0.001$ ).

To address the possibility that the observed elevations in NMRP [NO MOVE] activity were caused by intercurrent tremor, we compared network activity in 10 atremulous PD subjects, with corresponding values from 10 age- and severity-matched patients with observable tremor and from the eight healthy control subjects (see Materials and Methods). This analysis (Fig. 4A) revealed a significant group difference in NMRP [NO MOVE] expression $\left(F_{(2,25)}=4.793, p=0.017\right)$, with increases of similar degree in tremulous and atremulous PD patients relative to healthy subjects (Tremor $(+): p=0.034$, Tremor $(-): p=0.035$ ). There was no significant difference between patients with and without tremor $(p=1.0)$. Group differences in NMRP expression measured during motor execution (Fig. $4 B$ ) were not significant
$\left(F_{(2,25)}=1.421, p=0.260\right)$. However, a significant difference across the three groups (Fig. 4C) was present for the $\triangle$ NMRP [MOVE - NO MOVE] activation response $\left(F_{(2,25)}=7.533, p=0.003\right)$, with abnormally reduced activation responses in the tremulous PD subgroup $(p=0.002)$ and a trend-level reduction $(p=0.1)$ in the atremulous subgroup. No significant difference in $\triangle \mathrm{NMRP}$ values was present, however, across the two patient subgroups ( $p=0.293$ ).

\section{Longitudinal changes in NMRP expression}

Analysis of the longitudinal NMRP [NO MOVE] data (Fig. 5A) revealed a significant increase in network activity over time $\left(t_{(17)}=3.49, p=0.003\right)$. Pattern expression values were elevated at each time point relative to healthy control values (TP1: $t_{(18)}=2.11, p=0.049$; TP2: $t_{(18)}=$ 3.18, $p<0.005$; TP3: $t_{(12)}=2.79, p=$ 0.016 ; Student's $t$ test). Longitudinal increases in NMRP [MOVE] values (Fig. $5 B)$ were also present $\left(t_{(17)}=4.25, p<\right.$ 0.001 ), although pattern expression became significantly abnormal only at the last time point (TP1: $t_{(18)}=0.735, p=0.472$; TP2: $t_{(18)}=1.610, p=0.125 ;$ TP3: $t_{(12)}=3.68$, $p=0.003)$. Longitudinal changes in NMRP [MOVE] and [NO MOVE] values were found to be intercorrelated $(r=0.70$, $p<0.001$; Bland-Altman correlation), and $\triangle \mathrm{NMRP}$ [MOVE - NO MOVE] values (Fig. 5C) did not change significantly over the same time interval $\left(t_{(17)}=0.002, p=\right.$ $0.99)$.

\section{Changes in NMRP expression with treatment}

NMRP expression in NO MOVE scans (Fig. 6) was reduced by STN stimulation $\left(t_{(13)}=3.57, p=0.003\right)$, although network activity during treatment remained elevated relative to healthy control values (OFF: $t_{(20)}=3.71, p=0.001$; DBS: $t_{(20)}=2.64, p=$ 0.016 ; Student's $t$ test). The effects of STN stimulation on NMRP [MOVE] and $\triangle$ NMRP values (Fig. $6 B, C$ ) were not significant $(p>0.12)$. Despite producing a similar degree of motor benefit, levodopa treatment (Fig. 7A) did not alter NMRP [NO MOVE] expression $\left(t_{(13)}=1.22, p=0.25\right)$; abnormal elevations in these values were present both at baseline and with treatment (OFF: $t_{(20)}=3.13, p=0.005$; LD: $t_{(20)}=2.95, p=0.008$; Student's $t$ test). Levodopa administration had no effect $\left(t_{(13)}=-0.536, p=\right.$ 0.60 ) on NMRP [MOVE] values (Fig. $7 B$ ), although a marginal increase in $\triangle \mathrm{NMRP}$ (Fig. $7 C$ ) was observed with this intervention $\left.t_{(13)}=2.12, p=0.054\right)$.

\section{Correlates of abnormal NMRP expression in PD}

NMRP [NO MOVE] values measured in the baseline offmedication scans of the PD patients did not correlate with PDRP expression computed in metabolic images from the same subjects $(r=0.248, p=0.203)$. Analysis of the longitudinal data (Fig. $8 A)$ revealed that the changes in NMRP [NO MOVE] activity seen with disease progression were accompanied by concurrent in- 
creases in PDRP expression. Nonetheless, correlations between the two network measures were not significant at any of the longitudinal time points (TP1: $r=0.367$, $p=0.241$; TP2: $r=0.520, p=0.083$; TP3: $r=0.081, p=0.878)$. Likewise, the changes in these variables observed over time were not significantly correlated $(r=0.235, p=0.332$; Bland-Altman correlation). The progressive increases in UPDRS motor ratings seen in the longitudinal cohort correlated with concurrent changes in the activity of both networks (NMRP [NO MOVE]: $t_{(17)}=2.92, p=$ 0.01; PDRP: $t_{(17)}=2.13, p=0.04$; GLM). Indeed, clinical deterioration in these subjects was better predicted using the two network measures together in a single model than by the PDRP alone $\left(F_{(1,16)}=\right.$ $6.711, p=0.019)$. The bivariate model provided borderline improvement in clinical prediction compared with the NMRP alone $\left(F_{(1,16)}=3.174, p=0.094\right)$.

For the treatment cohort, correlations between NMRP [NO MOVE] and PDRP expression were also not significant when assessed at baseline (OFF: $r=0.129, p=$ 0.634; Pearson's correlation) or in the treated condition (ON: $r=0.160, p=$ 0.555). The correlation between treatment-mediated changes in the two network measures was, likewise, not significant $(r=-0.328, p=0.215)$. Treatment-mediated improvement in motor ratings (Fig. $8 B, C$ ) correlated with changes in the activity of both networks (NMRP: $t_{(15)}=2.67, p=0.018$; PDRP: $\left.t_{(15)}=2.33, p=0.034\right)$. When subject expression values for the two networks were entered together into a single model, the prediction of clinical outcome was more accurate than when either measure was evaluated individually $(p<0.016)$.

\section{Discussion}

\section{Increased NMRP expression in PD: deficient inhibition of} resting network activity

In this study, we used the NMRP, a previously characterized spatial covariance pattern associated with motor activation in normal subjects, as a quantitative probe of network activity in PD patients scanned during movement and in a sensory-matched nonmovement condition. In earlier studies, we have found that normal task-related activation patterns can be altered in disease states, especially if cognitive demand is high (Nakamura et al., 2001; Mentis et al., 2003a; Carbon et al., 2008). Nonetheless, with regard to simple motor execution, $\mathrm{PD}$ patients activated the same network as healthy subjects, with minimal violations of the MOVE $>$ NO MOVE ordinal trend. The validation steps that were undertaken to show that the NMRP was indeed deployed by the patients during movement, regardless of disease stage and treatment condition, and that pattern expression was stable in repeated trials, lend credence to the consistent elevations of motor network activity that were observed in the PD group. In this regard, the finding in $\mathrm{PD}$ of significant reductions in the $\triangle \mathrm{NMRP}$
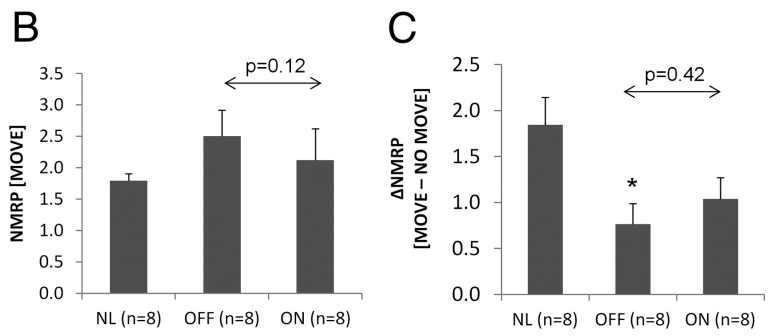

Figure 6. NMRP expression: effects of STN stimulation. $A$, NMRP expression measured in the NO MOVE scans of PD patients $\left(t_{(13)}=3.571, p=0.003\right)$. B, By contrast, NMRP expression measured during MOVE did not differ from control (NL) values in either $\left(0 \mathrm{~N}: t_{(14)}=-2.138, p=0.051\right)$. The treatment-mediated change in this measure was, however, not significant $\left(t_{(7)}=-0.849\right.$,
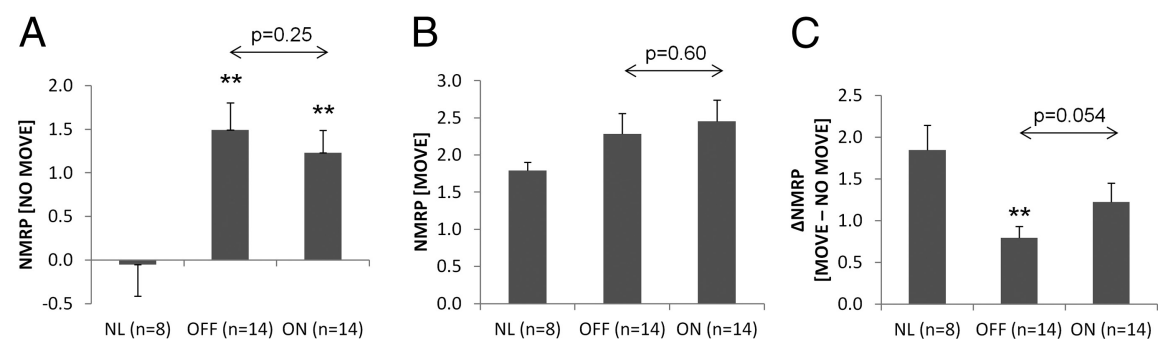

Figure 7. NMRP expression: effects of levodopa infusion. $\boldsymbol{A}$, NMRP expression measured in NO MOVE scans was abnormally vodopa treatment was observed on this measure $\left(t_{(13)}=1.217, p=0.245\right)$. $\boldsymbol{B}$, NMRP expression in MOVE scans did not differ values at baseline (0FF: $\left.t_{(20)}=-3.654, p=0.002\right)$ but not during treatment (0N: $\left.t_{(20)}=-1.654, p=0.114\right)$. Changes in $\triangle \mathrm{NMRP}$ with treatment were not significant $\left(t_{(13)}=-2.116, p=0.054\right) .{ }^{* *} p<0.01$, compared with NL (Student's $t$ test).

network activation response accords well with fMRI studies showing attenuated activation in the motor cortex of PD patients scanned during movement (Sabatini et al., 2000; Buhmann et al., 2003; Tessa et al., 2010). Surprisingly, however, when we explicitly quantified motor network activity in the MOVE and NO MOVE states, the disease-related changes were found to be greatest in the absence of movement.

The physiological basis for the abnormal NMRP elevations seen in PD is not known. It is tempting, however, to associate this phenomenon to pathologically increased synchronization of cortical-STN and corticostriatal discharges, as has been described consistently in relation to this disorder (Hammond et al., 2007; McCarthy et al., 2011; Moran et al., 2011). In particular, the akinetic-rigid manifestations of PD have been attributed to failure of the normal suppression of $\beta$-range oscillatory activity $(11-30 \mathrm{~Hz})$ in these pathways before movement onset (Tzagarakis et al., 2010; Zaidel et al., 2010; Crowell et al., 2012). Indeed, substantial evidence exists that antiparkinsonian interventions, such as STN stimulation and levodopa treatment, can improve symptoms of akinesia-rigidity by suppressing excessive synchrony in motor regions (Doyle et al., 2005; Zaidel et al., 2010; Weinberger and Dostrovsky, 2011). Along similar lines, the current findings are also compatible with the notion of deficient GABA-dependent cortical inhibition in PD (Cantello et al., 2002), which can also be ameliorated by treatment (Cunic et al., 2002; Fraix et al., 2008). 


\section{A Progression Cohort}

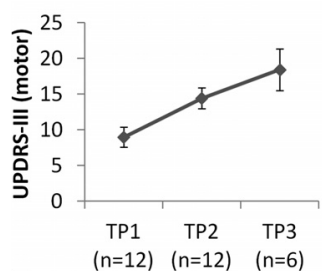

B DBS Effects ( $n=10)$

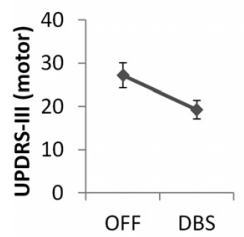

C Levodopa Effects ( $n=6)$

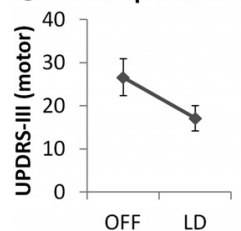

LD
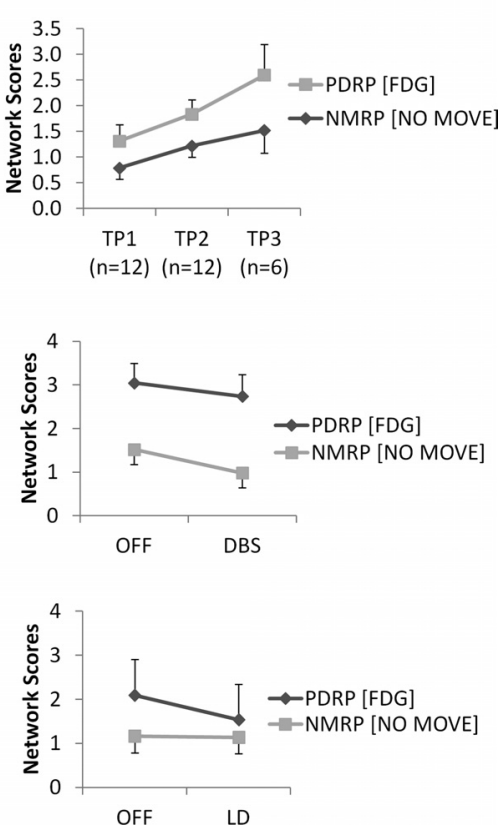

Figure 8. Clinical correlates of changing network activity. $\boldsymbol{A}$, In the progression cohort $(n=$ 12), the observed longitudinal increases in UPDRS motor ratings correlated with concurrent changes in NMRP [NO MOVE] $\left(t_{(17)}=2.92, p=0.01\right)$ and PDRP $\left(t_{(17)}=2.13, p=0.04\right)$ expression. When changes in the two networks were entered together into a single statistical model, the prediction of clinical outcome was more accurate than for each separately. $B, C$, Similarly, treatment-mediated improvement in motor ratings correlated with NMRP [NO MOVE] values $\left(t_{(15)}=2.67, p=0.0176\right)$ and with resting PDRP expression $\left(t_{(15)}=2.33, p=\right.$ 0.0342 ). As above, the two networks were more predictive in combination than when applied separately (see Results).

\section{NMRP and PDRP: two rest state networks in one disease}

Increases in NMRP activity with disease progression and concomitant reductions by treatment are reminiscent of similar changes in the expression of the abnormal PDRP network that have been described (Eidelberg, 2009; Niethammer and Eidelberg, 2012). Nonetheless, the current data indicate that the two networks behave independently with respect to these effects. In this vein, we note that the NMRP and PDRP topographies are spatially distinct (Fig. 1C), with $<7.5 \%$ correspondence between the regional loadings on the two networks. This minimal correspondence was not significantly different from pseudo-randomly generated volume-pairs with similar level of autocorrelation $(p=0.176)$. Indeed, a similarly small nonsignificant relationship, accounting for $<6 \%$ of the total subject score variance, was observed for the changes in the expression of these patterns that occurred over time and with treatment. The distinct nature of these two networks was highlighted by their clinical correlates. Specifically, individual differences in the progression of motor disability in the longitudinal cohort, and in the observed therapeutic response in the treatment cohort, were better explained using NMRP and PDRP expression values in concert, rather than by each network measure separately.

Although the correlations between changes in network activity and clinical motor ratings were similar for NMRP and PDRP, careful analysis revealed these relationships to be both independent and additive. This is particularly evident in the responses of the two networks to treatment. Although both STN DBS and levodopa provided a comparable degree of motor benefit, the former intervention was associated with relatively greater NMRP modulation than the latter. With respect to levodopa, one might consider the possibility that suppression of abnormal baseline NMRP activity during treatment was blunted by the concurrent induction of levodopa-induced dyskinesias. This is rather unlikely, however, given that levodopa-induced dyskinesias were evident during on-state $\mathrm{H}_{2}{ }^{15} \mathrm{O}$ PET imaging in only three of the 14 Group 2B subjects. Nonetheless, during infusion, NMRP [NO MOVE] values measured in these individuals did not influence the result reported for the entire group. Indeed, when the 14 levodopa treatment cases were ordered according to descending on-state NMRP [NO MOVE] expression, the three levodopainduced dyskinesia subjects ranked at or near the median values of the group. Similarly, measurements of NMRP [MOVE] and $\triangle$ NMRP [MOVE - NO MOVE] were also noninfluential for these individuals.

Conversely, levodopa treatment had relatively greater impact on resting PDRP expression than did STN stimulation. Overall, these findings accord with the consistent effects of STN stimulation on corticosubthalamic activity that have been described (e.g., Mure et al., 2012), with concomitant modulation of $\beta$-range synchronous oscillatory activity in motor regions. Although dopaminergic treatment can also restore deficient $\beta$-suppression in PD patients (Doyle et al., 2005; Weinberger and Dostrovsky, 2011), this intervention also reduces the abnormal synchronization of basal ganglia output activity that characterizes the pathological low-frequency oscillations seen in parkinsonism (Salenius et al., 2002; van Albada et al., 2009). This oscillatory system involves excessive synchronization of neurons in STN, internal globus pallidus, and ventrolateral thalamus, regions with salient contributions to the PDRP metabolic network (Lin et al., 2008; Eidelberg, 2009; Spetsieris and Eidelberg, 2011; Dhawan et al., 2012; Ma et al., 2012). Whether the observed responses of the two networks to different interventions reflect therapeutic effects on different oscillatory systems is unknown.

\section{Interpretative caveats}

A number of issues emerge in the interpretation of the current findings. From a practical standpoint, it is conceivable that, in PD patients, the abnormal elevations in NMRP activity seen in the absence of movement are simply a reflection of intercurrent tremor. This is unlikely, however, in that the PD participants were selected for predominant akinetic-rigid symptomatology and had minimal resting tremor during imaging. Moreover, we found that NMRP [NO MOVE] expression is elevated to very similar levels in severity-matched patient subgroups with and without clinically discernible tremor during the imaging session. Thus, it is improbable that tremor substantially impacted the current findings.

Another issue relates to the physiological interpretation of the NO MOVE state. In this condition, the subject visually attended to randomly appearing targets synchronized with auditory pacing tones (Ghilardi et al., 2000). Thus, NO MOVE belongs to a class of eyes-open rest states that require visual fixation. The metabolic scans, by contrast, were conducted in a less constrained eyes-open state in which visual fixation was not required. That said, recent fMRI studies have demonstrated similar patterns of rest state activity whether or not attention to a fixation target was required during the scans (Yan et al., 2009; Van Dijk et al., 2010). In this vein, we have observed nearly identical NMRP expression in $\mathrm{PD}$ patients scanned in NO MOVE, which requires visual fixation, and an unconstrained eyes-open nonmovement resting state (NO MOVE: $1.74 \pm 0.46$; eyes-open: $1.58 \pm 0.29 ; t_{(12)}=$ $0.266, p=0.794)$. Moreover, the eyes-open rest state was not concatenated with movement blocks, as were the NO MOVE 
trials. Therefore, the abnormal increase in network activity that was observed is unlikely to represent a "hangover" effect of prior motor task performance or cue-induced motor imagery. This possibility is less likely in the current study wherein $10 \mathrm{~min}$ were allowed to elapse between trial runs (Nakamura et al., 2001). Indeed, between-trial intervals of this length have been found to be adequate for recovery to pretask baseline after an interceding task block (Barnes et al., 2009).

Although NMRP and PDRP expression was quantified in comparable behavioral conditions, the network measurements themselves were obtained using different scanning techniques. We have previously reported dissociation of network activity values computed in scans of cerebral blood flow and metabolism obtained during levodopa treatment (Hirano et al., 2008), a finding recently substantiated in an experimental rat model (Ohlin et al., 2012). This phenomenon would likely obscure comparison of the levodopa-mediated changes in the expression of the two networks that were observed. Given that the vasomotor effects of levodopa are manifest strictly in the blood flow scans (Hirano et al., 2008), we chose PDRP values computed in the FDG PET scans as the basis for this comparison. Nevertheless, very similar results were obtained when PDRP subject scores were computed in the NO MOVE scans acquired with $\mathrm{H}_{2}{ }^{15} \mathrm{O}$ PET compared with when the network values were computed in the same subjects using their FDG PET scans. This was particularly striking for the progression cohort (main effect of time: $F_{(1,17)}=18.67$ and $F_{(1,17)}=$ 24.41 for PDRP [metabolism] and PDRP [blood flow], respectively, $p<0.001$ for both measures). Thus, the data suggest that the differences in PDRP and NMRP expression observed in PD patients cannot be attributed to differences in the imaging technique that was used to measure these values.

In conclusion, the findings show that the activity of the NMRP, a large-scale brain network associated with motor functioning in healthy subjects, is elevated in PD patients scanned in the absence of movement. This distinct systems-level abnormality was evident at the earliest clinical stages of the disorder, increasing in magnitude with disease progression. Moreover, the observed changes in NMRP expression were modulated by STN stimulation but not levodopa treatment. Comparisons of the NMRP changes with those occurring concurrently in the expression of the PDRP, a pathological rest state network expressed selectively in $\mathrm{PD}$ patients, suggests that the two networks provide independent and additive predictions of clinical outcome. That said, the impact of these network changes on other topographic features of the PD rest state is not known and will be addressed in future studies.

\section{References}

Argyelan M, Carbon M, Ghilardi MF, Feigin A, Mattis P, Tang C, Dhawan V, Eidelberg D (2008) Dopaminergic suppression of brain deactivation responses during sequence learning. J Neurosci 28:10687-10695. CrossRef Medline

Asanuma K, Tang C, Ma Y, Dhawan V, Mattis P, Edwards C, Kaplitt MG, Feigin A, Eidelberg D (2006) Network modulation in the treatment of Parkinson's disease. Brain 129:2667-2678. CrossRef Medline

Barnes A, Bullmore ET, Suckling J (2009) Endogenous human brain dynamics recover slowly following cognitive effort. PLoS One 4:e6626. CrossRef Medline

Berardelli A, Rona S, Inghilleri M, Manfredi M (1996) Cortical inhibition in Parkinson's disease: a study with paired magnetic stimulation. Brain 119: 71-77. CrossRef Medline

Bland JM, Altman DG (1995) Calculating correlation coefficients with repeated observations: 1. Correlation within subjects. BMJ 310:446. CrossRef Medline

Buhmann C, Glauche V, Stürenburg HJ, Oechsner M, Weiller C, Büchel C
(2003) Pharmacologically modulated fMRI: cortical responsiveness to levodopa in drug-naive hemiparkinsonian patients. Brain 126:451-461. CrossRef Medline

Cantello R, Tarletti R, Civardi C (2002) Transcranial magnetic stimulation and Parkinson's disease. Brain Res Brain Res Rev 38:309-327. CrossRef Medline

Carbon M, Felice Ghilardi M, Dhawan V, Eidelberg D (2007) Correlates of movement initiation and velocity in Parkinson's disease: a longitudinal PET study. Neuroimage 34:361-370. CrossRef Medline

Carbon M, Ghilardi MF, Argyelan M, Dhawan V, Bressman SB, Eidelberg D (2008) Increased cerebellar activation during sequence learning in DYT1 carriers: an equiperformance study. Brain 131:146-154. CrossRef Medline

Carbon M, Argyelan M, Habeck C, Ghilardi MF, Fitzpatrick T, Dhawan V, Pourfar M, Bressman SB, Eidelberg D (2010) Increased sensorimotor network activity in DYT1 dystonia: a functional imaging study. Brain 133:690-700. CrossRef Medline

Chen R, Garg RR, Lozano AM, Lang AE (2001) Effects of internal globus pallidus stimulation on motor cortex excitability. Neurology 56:716-723. CrossRef Medline

Crowell AL, Ryapolova-Webb ES, Ostrem JL, Galifianakis NB, Shimamoto S, Lim DA, Starr PA (2012) Oscillations in sensorimotor cortex in movement disorders: an electrocorticography study. Brain 135:615-630. CrossRef Medline

Cunic D, Roshan L, Khan FI, Lozano AM, Lang AE, Chen R (2002) Effects of subthalamic nucleus stimulation on motor cortex excitability in Parkinson's disease. Neurology 58:1665-1672. CrossRef Medline

Dhawan V, Tang CC, Ma Y, Spetsieris P, Eidelberg D (2012) Abnormal network topographies and changes in global activity: absence of a causal relationship. Neuroimage 63:1827-1832. CrossRef Medline

Doyle LM, Kühn AA, Hariz M, Kupsch A, Schneider GH, Brown P (2005) Levodopa-induced modulation of subthalamic $\beta$ oscillations during selfpaced movements in patients with Parkinson's disease. Eur J Neurosci 21:1403-1412. CrossRef Medline

Eidelberg D (2009) Metabolic brain networks in neurodegenerative disorders: a functional imaging approach. Trends Neurosci 32:548-557. CrossRef Medline

Fraix V, Pollak P, Vercueil L, Benabid AL, Mauguière F (2008) Effects of subthalamic nucleus stimulation on motor cortex excitability in Parkinson's disease. Clin Neurophysiol 119:2513-2518. CrossRef Medline

Ghilardi M, Ghez C, Dhawan V, Moeller J, Mentis M, Nakamura T, Antonini A, Eidelberg D (2000) Patterns of regional brain activation associated with different forms of motor learning. Brain Res 871:127-145. CrossRef Medline

Habeck C, Stern Y (2010) Multivariate data analysis for neuroimaging data: overview and application to Alzheimer's disease. Cell Biochem Biophys 58:53-67. CrossRef Medline

Habeck C, Krakauer JW, Ghez C, Sackeim HA, Eidelberg D, Stern Y, Moeller JR (2005) A new approach to spatial covariance modeling of functional brain imaging data: ordinal trend analysis. Neural Comput 17:1602-1645. CrossRef Medline

Hammond C, Bergman H, Brown P (2007) Pathological synchronization in Parkinson's disease: networks, models and treatments. Trends Neurosci 30:357-364. CrossRef Medline

Hirano S, Asanuma K, Ma Y, Tang C, Feigin A, Dhawan V, Carbon M, Eidelberg D (2008) Dissociation of metabolic and neurovascular responses to levodopa in the treatment of Parkinson's disease. J Neurosci 28:4201-4209. CrossRef Medline

Huang C, Tang C, Feigin A, Lesser M, Ma Y, Pourfar M, Dhawan V, Eidelberg D (2007) Changes in network activity with the progression of Parkinson's disease. Brain 130:1834-1846. CrossRef Medline

Hughes AJ, Daniel SE, Kilford L, Lees AJ (1992) Accuracy of clinical diagnosis of idiopathic Parkinson's disease: a clinico-pathological study of 100 cases. J Neurol Neurosurg Psychiatry 55:181-184. CrossRef Medline

Isaias IU, Marotta G, Hirano S, Canesi M, Benti R, Righini A, Tang C, Cilia R, Pezzoli G, Eidelberg D, Antonini A (2010) Imaging essential tremor. Mov Disord 25:679-686. CrossRef Medline

Lefaucheur JP (2005) Motor cortex dysfunction revealed by cortical excitability studies in Parkinson's disease: influence of antiparkinsonian treatment and cortical stimulation. Clin Neurophysiol 116:244-253. CrossRef Medline

Liebhold AM, Sharov AA (1998) Testing for correlation in the presence of 
spatial autocorrelation in insect count data. In: Population and community ecology for insect management and conservation (Baumgartner J, Brandmayr P, Manly BFJ, eds), pp 111-117. Rotterdam, The Netherlands: Balkema.

Lin TP, Carbon M, Tang C, Mogilner AY, Sterio D, Beric A, Dhawan V, Eidelberg D (2008) Metabolic correlates of subthalamic nucleus activity in Parkinson's disease. Brain 131:1373-1380. CrossRef Medline

Ma Y, Tang C, Spetsieris PG, Dhawan V, Eidelberg D (2007) Abnormal metabolic network activity in Parkinson's disease: test-retest reproducibility. J Cereb Blood Flow Metab 27:597-605. CrossRef Medline

Ma Y, Peng S, Spetsieris PG, Sossi V, Eidelberg D, Doudet DJ (2012) Abnormal metabolic brain networks in a nonhuman primate model of parkinsonism. J Cereb Blood Flow Metab 32:633-642. CrossRef Medline

McCarthy MM, Moore-Kochlacs C, Gu X, Boyden ES, Han X, Kopell N (2011) Striatal origin of the pathologic $\beta$ oscillations in Parkinson's disease. Proc Natl Acad Sci U S A 108:11620-11625. CrossRef Medline

McClullagh P, Nelder JA (1989) Generalized linear models, Ed 2. New York: Chapman and Hall.

Mentis MJ, Dhawan V, Feigin A, Delalot D, Zgaljardic D, Edwards C, Eidelberg D (2003a) Early stage Parkinson's disease patients and normal volunteers: comparative mechanisms of sequence learning. Hum Brain Mapp 20:246-258. CrossRef Medline

Mentis MJ, Dhawan V, Nakamura T, Ghilardi MF, Feigin A, Edwards C, Ghez C, Eidelberg D (2003b) Enhancement of brain activation during trialand-error sequence learning in early PD. Neurology 60:612-619. CrossRef Medline

Moeller JR, Habeck CG (2006) Reciprocal benefits of mass-univariate and bilinear modeling in brain mapping: applications to event-related functional MRI, $\mathrm{H}_{2}{ }^{15} \mathrm{O}$ - and FDG-PET. Int J Biomed Imag 2006:79862. CrossRef Medline

Moran RJ, Mallet N, Litvak V, Dolan RJ, Magill PJ, Friston KJ, Brown P (2011) Alterations in brain connectivity underlying $\beta$ oscillations in Parkinsonism. PLoS Comput Biol 7:e1002124. CrossRef Medline

Mure H, Hirano S, Tang CC, Isaias IU, Antonini A, Ma Y, Dhawan V, Eidelberg D (2011) Parkinson's disease tremor-related metabolic network: characterization, progression, and treatment effects. Neuroimage 54: 1244-1253. CrossRef Medline

Mure H, Tang CC, Argyelan M, Ghilardi MF, Kaplitt MG, Dhawan V, Eidelberg D (2012) Improved sequence learning with subthalamic nucleus deep brain stimulation: evidence for treatment-specific network modulation. J Neurosci 32:2804-2813. CrossRef Medline

Nakamura T, Ghilardi MF, Mentis M, Dhawan V, Fukuda M, Hacking A, Moeller JR, Ghez C, Eidelberg D (2001) Functional networks in motor sequence learning: abnormal topographies in Parkinson's disease. Hum Brain Mapp 12:42-60. CrossRef Medline

Niethammer M, Eidelberg D (2012) Metabolic brain networks in translational neurology: concepts and applications. Ann Neurol 72:635-647. CrossRef Medline

Ohlin KE, Sebastianutto I, Adkins CE, Lundblad C, Lockman PR, Cenci MA (2012) Impact of L-DOPA treatment on regional cerebral blood flow and metabolism in the basal ganglia in a rat model of Parkinson's disease. Neuroimage 61:228-239. CrossRef Medline

Pierantozzi M, Palmieri MG, Mazzone P, Marciani MG, Rossini PM, Stefani A, Giacomini P, Peppe A, Stanzione P (2002) Deep brain stimulation of both subthalamic nucleus and internal globus pallidus restores intracortical inhibition in Parkinson's disease paralleling apomorphine effects: a paired magnetic stimulation study. Clin Neurophysiol 113:108-113. CrossRef Medline

Pievani M, de Haan W, Wu T, Seeley WW, Frisoni GB (2011) Functional network disruption in the degenerative dementias. Lancet Neurol 10: 829-843. CrossRef Medline

Ridding MC, Inzelberg R, Rothwell JC (1995) Changes in excitability of motor cortical circuitry in patients with Parkinson's disease. Ann Neurol 37:181-188. CrossRef Medline

Sabatini U, Boulanouar K, Fabre N, Martin F, Carel C, Colonnese C, Bozzao L, Berry I, Montastruc JL, Chollet F, Rascol O (2000) Cortical motor reorganization in akinetic patients with Parkinson's disease: a functional MRI study. Brain 123:394-403. CrossRef Medline

Salenius S, Avikainen S, Kaakkola S, Hari R, Brown P (2002) Defective cortical drive to muscle in Parkinson's disease and its improvement with levodopa. Brain 125:491-500. CrossRef Medline

Spetsieris PG, Eidelberg D (2011) Scaled subprofile modeling of resting state imaging data in Parkinson's disease: methodological issues. Neuroimage 54:2899-2914. CrossRef Medline

Tang CC, Poston KL, Dhawan V, Eidelberg D (2010) Abnormalities in metabolic network activity precede the onset of motor symptoms in Parkinson's disease. J Neurosci 30:1049-1056. CrossRef Medline

Tessa C, Lucetti C, Diciotti S, Baldacci F, Paoli L, Cecchi P, Giannelli M, Ginestroni A, Del Dotto P, Ceravolo R, Vignali C, Bonuccelli U, Mascalchi M (2010) Decreased and increased cortical activation coexist in de novo Parkinson's disease. Exp Neurol 224:299-306. CrossRef Medline

Tzagarakis C, Ince NF, Leuthold AC, Pellizzer G (2010) $\beta$-Band activity during motor planning reflects response uncertainty. J Neurosci 30: 11270-11277. CrossRef Medline

Tzourio-Mazoyer N, Landeau B, Papathanassiou D, Crivello F, Etard O, Delcroix N, Mazoyer B, Joliot M (2002) Automated anatomical labeling of activations in SPM using a macroscopic anatomical parcellation of the MNI MRI single-subject brain. Neuroimage 15:273-289. CrossRef Medline

van Albada SJ, Gray RT, Drysdale PM, Robinson PA (2009) Mean-field modeling of the basal ganglia-thalamocortical system: II. Dynamics of parkinsonian oscillations. J Theor Biol 257:664-688. CrossRef Medline

Van Der Werf YD, Paus T (2006) The neural response to transcranial magnetic stimulation of the human motor cortex: I. Intracortical and corticocortical contributions. Exp Brain Res 175:231-245. CrossRef Medline

Van Der Werf YD, Sadikot AF, Strafella AP, Paus T (2006) The neural response to transcranial magnetic stimulation of the human motor cortex: II. Thalamocortical contributions. Exp Brain Res 175:246-255. CrossRef Medline

Van Dijk KR, Hedden T, Venkataraman A, Evans KC, Lazar SW, Buckner RL (2010) Intrinsic functional connectivity as a tool for human connectomics: theory, properties, and optimization. J Neurophysiol 103:297-321. CrossRef Medline

Weinberger M, Dostrovsky JO (2011) A basis for the pathological oscillations in basal ganglia: the crucial role of dopamine. Neuroreport 22:151156. CrossRef Medline

Yan C, Liu D, He Y, Zou Q, Zhu C, Zuo X, Long X, Zang Y (2009) Spontaneous brain activity in the default mode network is sensitive to different resting-state conditions with limited cognitive load. PLoS One 4:e5743. CrossRef Medline

Zaidel A, Spivak A, Grieb B, Bergman H, Israel Z (2010) Subthalamic span of $\beta$ oscillations predicts deep brain stimulation efficacy for patients with Parkinson's disease. Brain 133:2007-2021. CrossRef Medline 